\title{
The Use of Biomaterials in Islet Transplantation
}

\author{
Danielle J. Borg • Ezio Bonifacio
}

Published online: 12 July 2011

(C) The Author(s) 2011. This article is published with open access at Springerlink.com

\begin{abstract}
Pancreatic islet transplantation is a therapeutic option to replace destroyed $\beta$ cells in autoimmune diabetes. Islets are transplanted into the liver via the portal vein; however, inflammation, the required immunosuppression, and lack of vasculature decrease early islet viability and function. Therefore, the use of accessory therapy and biomaterials to protect islets and improve islet function has definite therapeutic potential. Here we review the application of niche accessory cells and factors, as well as the use of biomaterials as carriers or capsules, for pancreatic islet transplantation.
\end{abstract}

Keywords Type 1 diabetes · Islet transplantation · Islet niche $\cdot$ Biomaterial $\cdot$ Encapsulation

\section{Introduction}

Type 1 diabetes (T1D) is caused by the autoimmune destruction of pancreatic $\beta$ cells. Treatment is optimized insulin injections with regular monitoring of blood glucose concentration. Although insulin therapy has improved quality of life for patients, many patients suffer from hypoglycemic episodes [1], have suboptimal glycemic control which increases the risk of long-term diabetes complications [2], and prevalence of coma, seizure, or death [1]. Thus, replacement of islet $\beta$-cell mass is an attractive option for patients not only to avoid insulin injection, but also to avoid complications associated with T1D. Replacement of islet $\beta$ cells can be performed either

D. J. Borg $\cdot$ E. Bonifacio $(\square)$

Preclinical Approaches to Stem Cell Therapy/Diabetes,

Technische Universität Dresden, DFG-Center for Regenerative

Therapies Dresden, Cluster of Excellence,

Tatzberg 47/49,

01307 Dresden, Germany

e-mail: ezio.bonifacio@crt-dresden.de by whole pancreas or pancreatic islet transplantation. Pancreatic islet transplantation is technically much easier for the patient, but has variable long-term success [1]. This is largely due to the intravascular hepatic transplantation site and resultant blood-mediated inflammatory reactions [3], low oxygen tension [4], and immunosuppressive drugs [5-8]. Thus, improvements that include encapsulation, cotransplantation with accessory cells or factors with or without a biomaterial, and alternative transplantation sites have been suggested to improve islet function and survival, potentially without the need for immunosuppression. We will introduce the native islet niche, report the current status of pancreatic islet co-transplantation with accessory cells/ factors, and the use of biomaterials as islet carriers or for encapsulation. With respect to encapsulation, the reader is also referred to other reviews [9-11].

\section{Native $\beta$ Cells and Their Surrounds}

The five endocrine cell types that comprise the islets of Langerhans work as a micro-organ to maintain glucose homeostasis. The most important cell type for this function is the insulin-producing $\beta$ cell, which senses circulating nutrient levels in the blood and responds by secreting insulin [12].

$\beta$ Cells rely on pancreatic and non-pancreatic environments for cues that promote their function and number [12]. Within islets, a dense vascular network exists, which is essential for efficient insulin secretion and oxygen transfer. $\beta$ Cells interact with the endothelial cells of the capillary network via the vascular basement membrane. Mouse $\beta$ cells secrete vascular endothelial growth factor (VEGF-A) to promote vascular development, whereas the basement membrane secreted by the endothelial cells supports insulin gene expression and secretion and $\beta$-cell proliferation [13, 14]. Human islets contain a second basement membrane, 
the source of which is still unidentified $[15,16]$. Cell to cell contacts between $\beta$ cells, facilitated by several transmembrane proteins, are important for optimal insulin expression, content, and glucose-stimulated insulin secretion (GSIS) $[17,18] . \beta$ and $\alpha$ cells appear to have reciprocal secretory responses that cooperate to maintain glycemic stability [19]. Because of the $\beta$ to $\alpha$ cell blood flow, the relationship between insulin and glucagon secretion is hypothesized to be determined by $\beta$-cell paracrine effects on $\alpha$ cells. However, $\beta$ cells express glucagon receptors and these are involved in the glucose competence of $\beta$-cell insulin secretion [20]. The tight relationships between the major endocrine islet cells are supported by the tri-laminar architecture of human islets whereby one layer of $\beta$ cells appears to be sandwiched between two $\alpha$ cell-enriched layers [21]. Islets are also innervated with neurons from parasympathetic and sympathetic nervous systems. Interactions between parasympathetic neurons and $\beta$ cells activate specific receptors to promote GSIS. The opposite occurs from sympathetic neuronal input to inhibit insulin secretion [22].

In addition to interactions within the islet, the $\beta$ cell also receives important signals from non-pancreatic tissues. $\beta$ Cells are reported to interact with the liver, bone, fat, and gut [12]. Perhaps the best known example is the communication that occurs between the endocrine cells of the intestine and the $\beta$ cells. By binding to specific G-protein-coupled receptors on the $\beta$ cell, incretins, which are secreted by the enteroendocrine cells, stimulate insulin secretion [23].

Islet transplantation requires isolation of the islets from the remainder of the pancreas. This process involves enzymatic digestion of the pancreas and purification of the islets via density centrifugation [1], and destroys the vasculature and nerve distribution within islets. Moreover, connections to the rest of the pancreas and potentially outside the pancreas are also lost [24]. To recreate this $\beta$-cell niche shortly after transplantation is likely to be beneficial for $\beta$-cell function and survival.

\section{Islets and Growth Factors/Proteins}

\section{Vascular Endothelial Growth Factor (VEGF-A)}

Newly transplanted islets require the process of angiogenesis to establish adequate blood supply for survival post transplantation. This process occurs over a 2- to 4-week period in small $[25,26]$ and large animal [27] models, and is aided by the endothelial cell mitogen, VEGF-A. $\beta$ Cells secrete VEGF-A under normal conditions [13, 14, 28] and it has been shown in vitro that hypoxic conditions increase VEGF-A protein expression, which may act as the initiator of re-vascularization after transplantation [28]. It appears that $\beta$-cell production of VEGF-A is required for the formation of new vessels and a competent islet vasculature, because in animal models it is shown that increased blood flow and normoglycemia is achieved by VEGF-A transgene expression in transplanted islets, but not with exogenous VEGF-A treatment [29]. The importance of $\beta$-cell VEGF-A secretion was confirmed in a knockout VEGF-A mouse model in which VEGF-A-deficient islets had markedly reduced vascular density 1 month after they were transplanted into a nondiabetic (NOD)-severe combined immunodeficiency mouse [30].

\section{Extracellular Matrix Proteins}

The basement membrane contains several extracellular matrix proteins such as laminins and collagens that provide support for $\beta$-cell function via $\beta 1$ integrin receptors [1315]. The importance of extracellular membrane proteins was demonstrated by the observation that a laminin 5-rich matrix allows $\beta$-cell spreading via $\alpha 6 \beta 1$ integrins [31] with decreased apoptosis [32], enhanced expression of cell cycle proteins [33], and improved insulin secretion of rat $\beta$ cells $[31,33]$.

\section{Islets and Accessory Cells}

\section{Endothelial Cells}

Although $\beta$-cell signals are important for the vascular network and proper islet function, the source of endothelial cells can vary. Experimentally, it is shown that endothelial cells can be derived from progenitors in the bone marrow. Several studies have shown that endothelial reporter gene-positive cells are located within islets after transplantation of bone marrow from mice with endothelial reporter transgenes [34, 35]. It is further shown that islet graft vasculogenesis from bone marrow precursors is superior to tissue-derived vasculogenesis and results in better islet function post transplant [36]. The benefits of endothelial cell or endothelial precursor cells to transplanted islets have been investigated in diverse settings. Johansson et al. [37] combined the revascularization properties of endothelial cells and their ability to act as a barrier and created a human endothelial cell coating on human islets prior to transplantation in an effort to protect islets from instant blood-mediated inflammatory reactions (IBMIRs). When transplanted into mice, these composite grafts provoked less activation of coagulation and complement and less infiltrating immune cells than non-coated islets, providing proof of concept for such a strategy [37]. 


\section{Bone Marrow Cells}

Bone marrow cell transplantation is suggested as a therapy to improve islet function. In addition to possible immune protection, direct benefits to the islets have been shown. A study by Ianus et al. [38] observed that transplantation of male bone marrow cells expressing green fluorescent protein (GFP) into lethally irradiated female recipient mice resulted in positivity for $\mathrm{Y}$ chromosome and GFP in $1.7 \%$ to $3 \%$ of pancreatic islet cells. These cells also expressed certain $\beta$-cell genes and transcription factors, and the authors concluded that bone marrow stem cells can differentiate into $\beta$ cells. Hess et al. [39] noted a similar frequency of insulin-positive GFP-positive cells but did not ascribe this to direct differentiation. Other reports could not confirm differentiation of bone marrow cells into $\beta$ cells in pancreatic injury and transplant models [40]. In these studies, migration to the pancreas was observed in addition to the amelioration of hyperglycemia and a partial or significant increase in $\beta$-cell mass, but no transdifferentiation of cells into $\beta$ cells was seen [40]. Collectively, these studies indicate that bone marrow cells do not differentiate into $\beta$ cells, but indirectly support $\beta$-cell function by either adopting a hematopoietic or endothelial cell fate or evoking the proliferation of recipient endothelial cells [40].

\section{Mesenchymal Stromal Cells}

One subset of progenitor cell that can be isolated from bone marrow are multipotent mesenchymal stromal cells (MSCs). These are a heterogenous population that can differentiate into cell types of the mesoderm embryonic lineage (osteoblasts, chondrocytes, and adipocytes), and experimentally have been shown to have wider differentiation capacity. In vitro they adhere and proliferate on tissue culture plastic in colonies and maintain a fibroblast-like morphology. The interaction between MSCs and islets was demonstrated by Sordi et al. [41], who showed in a bone marrow transplantation model that GFP-positive bone marrow cells migrated to islets and, once isolated, demonstrated an MSC phenotype and the ability to differentiate into osteoblasts. Following this, studies using induced diabetes mouse models confirmed that MSC-islet cotransplantation not only reversed diabetes but also significantly increased the number of recipient islets [42, 43]. Similarly, co-infusion of MSCs with a small number of islets allowed the return of normoglycemia and, moreover, an increase in capillary density was noted in these grafts compared with islets alone [44]. Other in vitro studies show that islets co-cultured with MSCs have higher levels of antiapoptotic signaling molecules [45] and hypoxia-resistant molecules under hypoxic conditions [46].
MSCs also have immunoregulatory activities. With respect to islet transplantation, it was shown that a murine stromal cell line was able to prevent graft rejection in a major histocompatibility complex-mismatched islet transplantation model [47]. Matrix metalloproteinases (MMPs), specifically MMP-2 and -9 , were speculated to mediate the protective effects seen after in vivo administration of MSCs with allogenic islets [48]. Furthermore, it was found that MSCs were capable of reducing islet infiltration and maintaining interleukin-10-secreting regulatory (FOXP3 ${ }^{+}$) T cells in an autoimmune diabetes model [49]. These results were extended to a non-human primate model in which allo-MSC infusion-increased peripheral T-regulatory cells coincided with stable islet allograft function [50].

In view of the numerous avenues to protect islet cell grafts and improve their function, it follows that strategies to implement and optimize the addition of growth factors, proteins, and accessory cells to islets should be considered. Also, carriers to co-localize islets and their support factors should be explored.

\section{Improving an Islet's Home}

\section{Comfort and Guidance}

The housing of islets within a biomaterial at alternate transplantation sites is a potential therapeutic option. Material for such a therapy can be biologically derived or synthetically made. In the past few years there has been a propensity to focus on the glycosaminoglycan, heparin, and synthetic biodegradable materials as carriers for islet endocrine cells.

\section{Heparin}

Heparin is a complex polymer that interacts with numerous enzymes and proteins in the body. Heparin is commonly used as an anticoagulant, but also contains binding sites for several growth factors and chemokines [51]. Heparin binding has previously been used to improve the biocompatibility of biomaterials for transplantation. Under this concept, Johansson et al. [37] directly heparinized the surface of islets to render them blood biocompatible. By immobilizing heparin to islets, they reasoned that this could inhibit coagulation and complement activation thereby reducing IBMIRs and intraportal islet loss. Using a biotin and avidin coating approach, they were able to transplant heparinized islets into a diabetic mouse and pig model. Blood glucose of mice transplanted with heparinized islets was normalized 10 days post-transplantation and a decrease in intraluminal clotting was observed in pigs transplanted with heparinized islets compared with untreated islets [52]. 
It was subsequently shown that VEGF-A could be attached to heparinized islets without affecting insulin secretion and that in vitro the VEGF-A acted as an endothelial cell attractant [53••].

Self-assembling amphiphile peptides bound to heparin [54] have also been used as a growth factor delivery system for islet transplantation [55]. Using a diabetic mouse model, islets were transplanted into the omentum pouch alone, with local administration of VEGF-A and basic fibroblast growth factor (FGF) or together with heparin-coated poly (L-lactic acid/lactide) (PLA) matrices with or without VEGF-A and FGF. A higher proportion of mice transplanted with biofunctionalized heparin-PLA scaffolds achieved normoglycemia and an increase in vessel density at the transplantation site, when compared to islets with or without administration of growth factors or heparin-PLA scaffolds [55]. Furthermore, this group recently showed that the biofunctionalized heparin-binding peptides could attach to isolated murine islets and increase islet viability, insulin secretion, and endothelial cell sprouting from within the islet [56]. These encouraging results with heparin suggest that synthetic materials with the ability to incorporate heparin and mimic the natural environment without eliciting an immune response (e.g., poly(ethylene glycol) [PEG] hydrogels) may improve islet transplantation outcome [57]. A variety of synthetic biomaterials has been used for islet culture and transplantation (Table 1) and is discussed below.

\section{Lactic Acid-Based Polymers}

Based on the small organic molecule, lactic acid polymers (PLA) can be easily manipulated during production or postpolymerization to produce a material with varying properties [58]. We have already discussed its use in combination with heparin-binding nanostructures. One copolymer that has been used in animal models of islet transplantation derives from a mixture of lactide and glycolide, poly(lacticco-glycolic acid) (PLGA). One notable feature of PLGA is the ability to decrease degradation time by increasing the ratio of glycolide to lactide [58].

The use of these polymers with islets was published in 2005. PLGA scaffolds with a ratio of $90 \%$ glycolide to $10 \%$ lactide (Vicryl ${ }^{\circledR}$; Ethicon Inc., Somerville, NJ) were coated with varying numbers of islets in a matrigel suspension and transplanted into the epididymal fat pad of diabetic mice. More mice were able to achieve normoglycemia when transplanted with the islet-matrigel-coated scaffold when compared with free islets or islets in matrigel suspension, and insulin content in transplanted islet-matrigel-coated scaffolds was similar to that of islets transplanted under the kidney capsule [59]. Modifications to this approach have included PLGA scaffolds with interconnected pores from 250 to $400 \mu \mathrm{m}$ so as to house a marginal islet mass for transplantation. Mice receiving such grafts into the folds of intraperitoneal fat achieved normoglycemia at a faster rate than mice receiving islets alone in the same location [60]. Another study used the commercially available Ethisorb ${ }^{\circledR}$ (Codman, Raynham, MA), comprised of Vicryl ${ }^{\circledR}$ with a poly-p-dioxanone (PDS) backing, to determine islet graft survival into the omentum pouch of pancreatectomized dogs. Four animals received autologous islets seeded into the polymer scaffold and two received free islets into the omentum pouch. All four animals transplanted with the scaffold and none of the control animals achieved normoglycemia without the administration of exogenous insulin secretion for a maximum of 5 months [61•].

\section{Other Polyesters}

Polyhydroxyalkanoates (PHA) are polyesters produced by microorganisms in unfavorable growth conditions and have been commonly used in many medical devices. Copolymers of 3-hydroxybutyrate and 3-hydroxyhexanoate (PHBHHx) were used in a pilot study to determine the effect of $\mathrm{PHBHHx}$ on cluster formation and insulin secretion of the murine islet $\beta$-cell line NIT-1. After overnight culture, cell clustering and later islet-like aggregates were seen in wells containing PHBHHx. Cells cultured on PHBHHx had increased insulin secretion and viability compared to islets with tissue culture alone, PLA, and another PHA copolymer derivative [62].

\section{Hydrogels}

Hydrogels, as the name implies, consist of highly absorbent polymers. By varying the amount of crosslinking of synthetic hydrogels, mechanical properties of the hydrogels can be attuned. A class of covalently linked hydrogel is based on the synthetic polymer PEG. The characteristics of PEG hydrogels include low immunogenicity, protein absorption, and cell adhesion. In a cell transplantation setting, these bio-inert properties can be modified by binding growth factors and incorporating cell attachment and enzyme-sensitive peptide sequences to allow the cells of interest to attach, proliferate, and function [63]. Furthermore, copolymers of PEG can be formed to create an amphiphilic polymer that has both hydrophobic and hydrophilic properties. Ito and Taguchi [64] used such a modification by incorporating oleyl hydrophobic tails to crosslink rat insulinoma cells to form spheroids and found that oleyl-O-PEG crosslinked cells were more glucose responsive than non-crosslinked cells.

Another synthetic polymer with similar properties to that of PEG hydrogels is the poly(vinyl alcohol) (PVA) hydrogel. In a recent report, PVA was modified with thiol-alkyl side chains to allow attachment to the lipid bilayer of endocrine islet cells and further conjugation of protein- 
Table 1 Synopsis of reports of pancreatic islet cells with biomaterial carriers

\begin{tabular}{|c|c|c|c|}
\hline Biomaterial type & In vitro outcome & In vivo outcome & Reference \\
\hline Heparin & $\begin{array}{l}\text { Attachment via biotin-avidin } \\
\text { interaction }\end{array}$ & $\begin{array}{l}\text { Normalized blood glucose in } \\
\text { diabetic mice. Decreased } \\
\text { intraluminal clotting in pigs }\end{array}$ & Cabric et al. [52] \\
\hline Heparin + VEGF-A & $\begin{array}{l}\text { Normal insulin secretion maintained. } \\
\text { Attracted endothelial cells }\end{array}$ & - & Cabric et al. $[53 \bullet \bullet]$ \\
\hline $\begin{array}{l}\text { Heparin-PLA + } \\
\text { VEGF-A + FGF }\end{array}$ & - & $\begin{array}{l}\text { Normalized blood glucose levels in } \\
\text { mice. Increase in blood vessel } \\
\text { density }\end{array}$ & Stendahl et al. [55] \\
\hline $\begin{array}{l}\text { Heparin-PLA + } \\
\text { VEGF-A + FGF }\end{array}$ & $\begin{array}{l}\text { Attachment on islets. Increased islet } \\
\text { viability and insulin secretion. } \\
\text { Initiated islet endothelial cell } \\
\text { sprouting }\end{array}$ & - & Chow et al. [56] \\
\hline PLGA-matrigel & - & $\begin{array}{l}\text { Normalized blood glucose levels in } \\
\text { diabetic mice with comparable } \\
\text { insulin secretion to islets under the } \\
\text { kidney capsule }\end{array}$ & Dufour et al. [59] \\
\hline PLGA & - & $\begin{array}{l}\text { Normalized blood glucose levels in } \\
\text { mice. Comparable results to islets } \\
\text { under the kidney capsule }\end{array}$ & Blomeier et al. [60] \\
\hline Ethisorb $^{\circledR}$ (PLGA + PDS) & - & $\begin{array}{l}\text { Normalized pancreatectomized } \\
\text { canine blood glucose for } 2(50 \%) \\
\text { and } 5(25 \%) \text { months without } \\
\text { exogenous insulin administration }\end{array}$ & Kin et al. $[61 \bullet]$ \\
\hline PHBHHx & $\begin{array}{l}\text { Cell clustering and islet-like aggre- } \\
\text { gates of NIT- } 1 \text { cells within } 72 \mathrm{~h} \\
\text { with an increase in insulin secre- } \\
\text { tion and viability }\end{array}$ & - & Yang et al. [62] \\
\hline Oleyl-O-PEG & $\begin{array}{l}\text { Crosslinked RIN cells into } \\
\text { spheroids, insulin secretion was } \\
\text { increased }\end{array}$ & - & Ito and Taguchi $[64]$ \\
\hline PVA-alkyl + urokinase & $\begin{array}{l}\text { Attachment on islets with } \\
\text { fibrinolytic activity and } \\
\text { comparable insulin secretion }\end{array}$ & - & Totani et al. [65] \\
\hline NIPA + laminin 5 & $\begin{array}{l}\text { Single rat islet cells cultured as a } \\
\text { sheet remained viable and glucose } \\
\text { responsive }\end{array}$ & $\begin{array}{l}\text { Insulin and glucagon } \\
\text { immunostaining were present } \\
7 \text { days post-transplantation }\end{array}$ & Shimizu et al. [66] \\
\hline
\end{tabular}

Ethisorb $^{\circledR}$ (Codman, Raynham, MA)

$F G F$ fibroblast growth factor; NIPA poly( $N$-isopropylacrylamide); $P D S$ poly- -dioxanone; $P E G$ poly(ethylene glycol); $P H B H H x$ 3-hydroxybutyrate and 3-hydroxyhexanoate; PLA poly(L-lactic acid/lactide); PLGA poly(lactic-co-glycolic acid); PVA poly(vinyl alcohol); $V E G F-A$ vascular endothelial growth factor

attracting maleimide and urokinase, which displays fibrinolytic activity. Treated islets were able to secrete insulin comparable with untreated and PVA-alkyl islets in vitro and showed increased fibrinolysis, suggesting that they could potentially dampen IBMIRs [65].

Unlike the above hydrogels, poly( $N$-isopropylacrylamide) (NIPA) polymer gels are thermo-responsive, undergoing a volume change at about $34^{\circ} \mathrm{C}$. A tissue engineering approach was performed by Shimizu et al. [66], in which isolated rat islets were trypsinized to form single cell suspensions and seeded onto NIPA hydrogels. Various extracellular matrix coatings were used to enhance attachment in vitro, with laminin 5 favoring viability and insulin secretion by single $\beta$ cells. After $48 \mathrm{~h}$ of culture, the islet cell sheets were placed at $20^{\circ} \mathrm{C}$ to allow removal and were transferred to a support membrane for syngeneic transplantation. Weak insulin and glucagon staining were observed 7 days post-transplantation [66]. Although further functional data were not shown, this report acts as a proof of concept that thermo-reactive NIPA polymers could potentially be used as an alternate delivery system for islet transplantation.

\section{Biopolymer Films}

To determine the best substrate for islet survival and function, a high-throughput approach was taken by Williams et al. [67] and Mei et al. [68•]. In Williams et al.'s group [67], films from different materials were cast or coated as a monolayer on tissue culture plastic and seeded 
with small clusters of dispersed rat islets. Films were then graded by the number of attached islet clusters. Laminin coatings and mildly hydrophobic polymers (e.g., low molecular weight PLGA) performed well, in addition to double layer coatings, which were comprised of PLGA on the bottom with a second material (carboxyl groups, methylesters) on top. Islet cell morphology appeared spread and ruffled and when cells were added in multiple layers, cells of all layers remained viable for 7 days [67]. The group of Mei et al. [68 ${ }^{\bullet}$ analyzed a microarrayed library of 496 different polymers, comprised of 22 different acrylate monomers in different combinations. Monomers were chosen with a range of chemical groups, crosslinking density and varying hydrophobicity and hydrophilicity to generate chemically diverse polymers. Attachment of islet cells was supported by few polymers with distinct characteristics. The findings were confirmed in another set of polymers [68 ${ }^{\bullet}$. Further studies are required to determine whether the dispersed attached $\beta$ cells are still glucose responsive in vitro and whether polymers as a transplantation unit for islets could improve glycemia in diabetic animal models.

\section{Protection and Security}

A major drawback of islet transplantation is the immunosuppression that is required to prevent transplant rejection. Not only does this cause undesired side effects to the immune system, the immunosuppressive drugs also have detrimental effects on islet function and survival [5-8]. Since the late 1970s, researchers have pursued encapsulating both allo- and xeno-derived islets via different methods, as a means of protecting the islets and potentially eliminating the need for immunosuppression [9]. The concept of encapsulation involves separating the transplanted cells from the host immune system by a semipermeable, biocompatible membrane. The membrane should contain pores small enough to prevent entry of inflammatory cells and large proteins, such as antibodies, but large enough to allow transfer of nutrients, oxygen, and hormones [10]. To date, three types of encapsulation systems have been studied by researchers in the field.

\section{Extravascular Chambers}

Pioneering islet transplantation animal studies using planar or tubular diffusion chambers in the early 1980s produced variable results due to varying hormone diffusion capabilities of the membranes used and overgrowth of fibroblasts in the graft and/or chamber. The main advantage of these devices was the ease of graft chamber retrieval from the various extravascular transplantation sites. However, the drawback was the decrease in islet function due to fibrosis, lack of immediate vascularization, and extended nutrient/ hormone diffusion time, brought about by the design of these chambers [69]. The use of smooth polyacrylonitrilepolyvinyl chloride (PAN-PVC) membranes in the 1990s markedly decreased the adhesion and fibrosis seen in these earlier studies [9]. In an isolated clinical study, as a proof of concept, patients with diabetes were transplanted with a marginal mass of allogenic islets in chambers at a subcutaneous site without immunosuppression. The chambers were biocompatible and after 2 weeks, grafts were removed and islets were still glucose responsive [70].

Research since this time has concentrated on optimizing chamber designs [71, 72], improving vascularization; either by treating with growth factors pretransplantation [73] or at the time of transplantation [74, 75] or implanting the device prior to islet insertion [76] or improving oxygen transfer $[77 \bullet \bullet]$. For example, a recent study showed islet function retention of allogeneic pig islets contained within a subcutaneous transplanted, oxygen-refueled macrochamber ( $\beta$ Air device). This device was comprised of a chamber that provided oxygen supply through a gas-permeable membrane to the alginate immobilized islets, which were immunoprotected by a Teflon membrane (against cellular invaders) and a mannuronic acid-alginate-coated Teflon membrane (against antibody and complement penetration). They showed the device was biocompatible after 13 days with no local inflammatory or fibrotic reactions and that the islets maintained similar insulin secretion levels when compared with levels prior to transplantation [77••].

Progress is still required for the successful translation of extravascular grafts to the clinic; specifically, accurate chamber design to reduce membrane stress and breakage [9], improvement of the graft vascularization, and a transplantation site that is minimally evasive to allow for removal to replace exhausted islets, if required $[9,10]$.

\section{Intravascular Chambers}

Around the time of extravascular device transplantation, the notion of connecting small chambers to the host vascular system and separating islets with an immunoprotective membrane received attention [9]. These intravascular devices overcame the diffusion oxygenation and nutrition limitations due to a closer proximity to the blood [69]. The first reports to use such a system achieved normoglycemia in autologous diabetic rat [78, 79] and monkey models [79]. Further studies by these groups [80-82] and others [69] improved chamber design to decrease coagulation and demonstrated functional allogeneic $[80,81]$ and xenogeneic $[69,82]$ islet grafts, without the use of immunosuppression. However, exogenous insulin was still required [82]. A modified approach was taken by Cronin et al. [83] in a diabetic mouse model, which involved running a portion of 
the femoral artery though the lumen of a silicone tube, which was filled with a Matrige ${ }^{\circledR}$ (BD Biosciences, Franklin Lakes, NJ) solution supplemented with FGF and heparin [84] or Gelita-Spon ${ }^{\circledR}$ (Gelita Medical BV, Amsterdam, Netherlands) supplemented with nerve growth factor (NGF) [85]. In the matrigel study, islets were seeded at the time of implantation or 3 weeks after prevascularization of the chamber. Only the islets in the prevascularized chamber could improve glycemia of the mice [84]. Interestingly, the later study demonstrated that prevascularization of the chamber was not required when syngeneic islets were seeded with NGF. In this condition, $80 \%$ of mice achieved normoglycemia compared with $0 \%$ of mice receiving islets on the gelatin sponge alone [85]. This system takes advantage of an easily vascularized transplantation site, which allows optimal diffusion while eliminating protein deposition and coagulation around the graft.

\section{Microencapsulation}

Microencapsulation allows single or groups of islets to be immunoisolated from the host system via spherical droplets/beads or multilayering systems. This form of encapsulation has been the most intensely studied over the past three decades due to ease of production, mechanical stability, large surface-to-volume ratio, and optimal diffusion capability [10]. The size of the microspheres in early studies ranged from 600 to $800 \mu \mathrm{m}$; however, recent fabrication techniques have allowed $350-$ to $500-\mu \mathrm{m}$ microspheres to be produced [86]. Hydrogels including alginate, poly(hydroxyethyl methacrylate-methyl methacrylate), agarose, acrylonitrile copolymers, chitosan, and PEG are the most frequently used materials for microencapsulation [10]. To date, the most preferred biomaterial for microencapsulation is based on alginate. Alginate consists of linear copolymers comprised of $\beta-D$-mannuronic and $\alpha$-L-guluronic acids. It is the various combinations of these polymers that solidify around the islet(s) in a divalent cationic solution. Various coatings (e.g., poly- $L$ lysine) to improve mechanical stability and improve biocompatibility of these microcapsules have also been extensively studied [10].

Achievement of normoglycemia was seen in early studies with alginate-based encapsulated allogeneic [9, 87] and xenogenic [88, 89] islets transplanted into diabetic rodent models. However, attempts to upscale this system to larger animal models were inconsistently successful [90]. Soon-Shiong et al. reported both in a diabetic dog [91] and one T1D patient [92] that insulin independence could be achieved for up to 5.5 and 9 months, respectively, by transplantation of encapsulated allogeneic islets and treatment with cyclosporine. However, others reported an
Fig. 1 Biomaterial carrier for islet transplantation. An optimal biomaterial for human islet transplantation would be one with large pore sizes to accommodate islets, as well as providing the possibility to be biofunctionalized with growth factors and potentially immunosuppressive drugs, and with adhesion molecules so that accessory cells can be localized and with enzyme degradation sites for eventual degradation, allowing a functional revascularized islet micro-organ to remain at the transplantation site. (Adapted from Lutolf and Hubbell [98].)

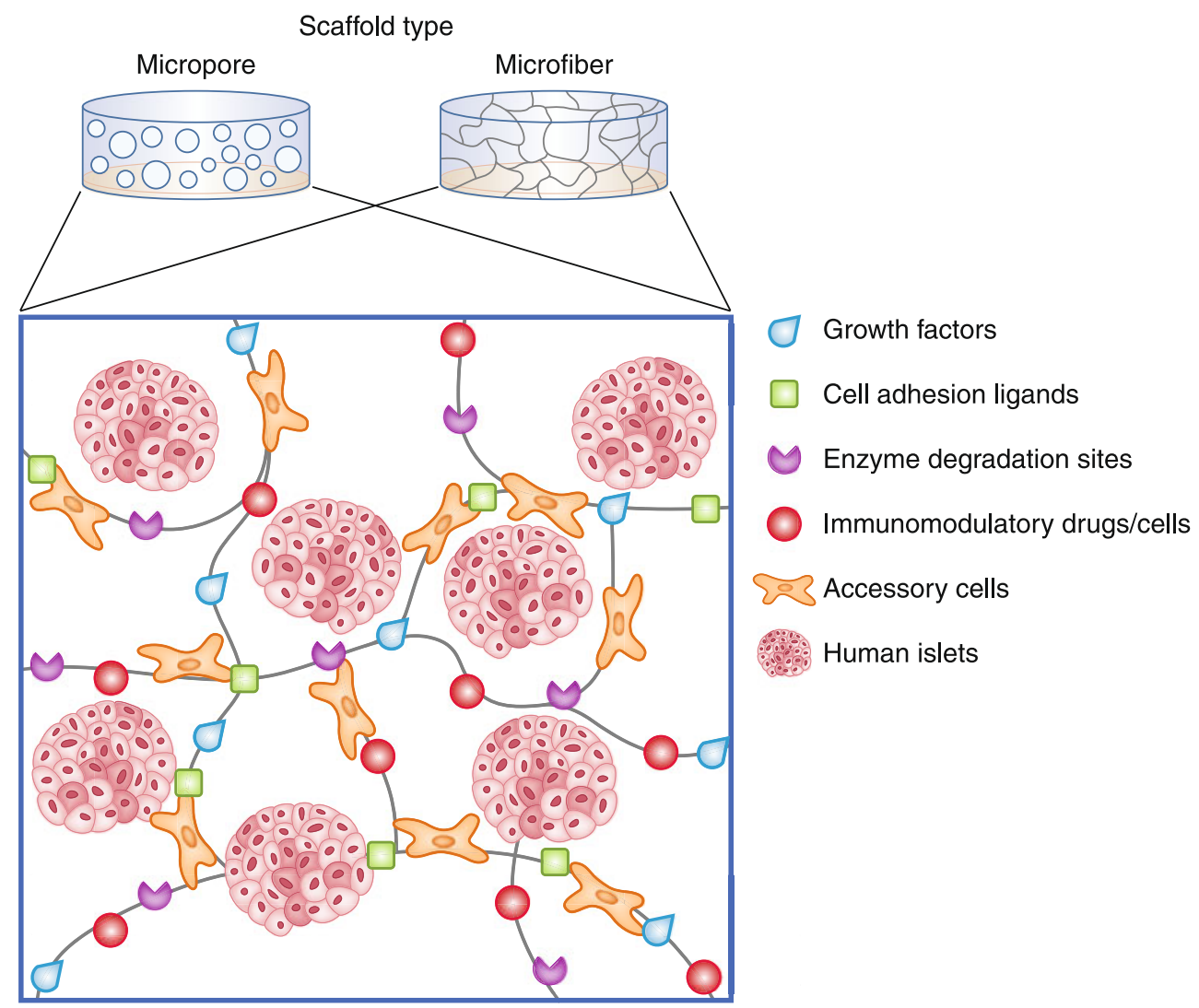


inability to achieve full remission of hyperglycemia in diabetic dogs transplanted with auto-, allo-, or xenogeneicencapsulated islets. The later studies did not use immunosuppression but the authors speculated that the decrease in transplanted islet-to-surface ratio and fibrotic overgrowth affected the efficiency of these grafts [90].

Whether immunosuppression is required to prolong microencapsulated islets is debated. In an ideal situation, encapsulated allogeneic or xenogenic islets would have long-term survival with minimal immune response and no requirement for immunosuppression. However, the microcapsule fabrication and composition have fallen short of this expectation [93]. Recent reports are now attempting to combine microcapsule optimization with immunosuppression to determine whether graft function can be extended. For example, Safley et al. [94, 95] observed that inhibition of T-cell costimulatory molecules CD28/B7 by CTLA-Ig in NOD mice transplanted with microencapsulated porcine islets extended graft function compared with no treatment. Similar results were also seen elsewhere [96]. Safley et al. $[94,95]$ showed that empty microcapsules did not elicit an immune response and it was the presence of the xenogenic islets that attracted large numbers of leukocytes to the transplantation site. Others showed that the composition of the microcapsules also affects the biocompatibility of the microcapsule [93]. In this report, cyclosporin A treatment of rats transplanted with low or high guluronic acid alginate bovine-encapsulated islets increased the longevity of the graft by at least twofold. Cyclosporin A decreased the amount of fibrotic overgrowth on the low guluronic alginate, with similar results in empty microcapsules [93]. Much of the experimental work with alginate microcapsules has used nonstandardized and varying alginate compositions with varying results [10]. Clinical application, conversely, requires clinical-grade alginate and rigorous evaluation of the product [97]

\section{Conclusions}

Pancreatic islet transplantation has come a long way in almost 40 years, but is still generally considered an experimental procedure. Advances in the fields of material science, nanotechnology, immunology, and islet transplantation have been able to shed some light on how we might be able to improve long-term survival and function of pancreatic islet transplants. What's next? We think it would be beneficial to use the knowledge of $\beta$-cell interactions within its native environment and recreate this islet niche as best as possible in a carrier or capsule (Fig. 1). We envision creating a "microenvironment" for human islets that would include not only the islets, but accessory cells, proteins, and possibly local immunosuppression housed within a bio- compatible material. The material would support islets for the time required for the body to recreate a supportive microenvironment around the transplantation site and eventually be degraded so that a suitable islet micro-organ would remain. These activities provide the alternative for human islets and must be complemented by efforts in encapsulation so that other sources of $\beta$ cells (e.g., xenogeneic islets and stem cell-derived $\beta$ cells) can also find their way to clinical therapy.

Acknowledgments This work was supported by the DFG-Center for Regenerative Therapies Dresden, Cluster of Excellence (FZT 111) and the Federal Ministry of Education and Research, Germany (01GN0945). D. J. Borg is enrolled in the Regenerative Medicine $\mathrm{PhD}$ Program of the Dresden International Graduate School for Biomedicine \& Bioengineering (DIGS-BB) as part of the Technical University of Dresden.

Disclosure No potential conflicts of interest relevant to this article were reported.

Open Access This article is distributed under the terms of the Creative Commons Attribution Noncommercial License which permits any noncommercial use, distribution, and reproduction in any medium, provided the original author(s) and source are credited.

\section{References}

Papers of particular interest, published recently, have been highlighted as:

- Of importance

•- Of major importance

1. Merani S, Shapiro AMJ. Current status of pancreatic islet transplantation. Clin Sci (Colch). 2006;110:611-25.

2. The Diabetes Control and Complications Trial Research Group. The effect of intensive treatment of diabetes on the development and progression of long-term complications in insulin-dependent diabetes mellitus. New Engl J Med. 1993;329:977-86.

3. The Expert Committee on the Diagnosis and Classification of Diabetes Mellitus. Report of the expert committee on the diagnosis and classification of diabetes mellitus. Diabetes Care. 2002;25 suppl 1:s5-s20.

4. Jansson L, Carlsson PO. Graft vascular function after transplantation of pancreatic islets. Diabetologia. 2002;45(6):749-63.

5. Desai N, Goss J, Deng S, et al. Elevated portal vein drug levels of sirolimus and tacrolimus in islet transplant recipients: local immunosuppression or islet toxicity? Transplantation. 2003;76(1):1623-5.

6. Zahr E, Molano R, Pileggi A, et al. Rapamycin impairs in vivo proliferation of islet beta-cells. Transplantation. 2007;84(12): 1576-83.

7. Zhang N, Su D, Qu S, et al. Sirolimus is associated with reduced islet engraftment and impaired $\beta$-cell function. Diabetes. 2006; 55(9):2429-36.

8. Cantaluppi V, Biancone L, Romanazzi GM, et al. Antiangiogenic and immunomodulatory effects of rapamycin on islet endothelium: relevance for islet transplantation. Am J Transplant. 2006;6 (11):2601-11. 
9. Lanza RP, Hayes JL, Chick WL. Encapsulated cell technology. Nature. 1996;14:1107-11.

10. de Vos P, Faas MM, Strand B, et al. Alginate-based microcapsules for immunoisolation of pancreatic islets. Biomaterials. 2006;27 (32):5603-17.

11. Teramura Y, Iwata H. Bioartificial pancreas- microencapsulation and conformal coating of islet of langerhans. Adv Drug Deliv Rev. 2010;62(7-8):827-40.

12. Eberhard D, Lammert E. The pancreatic $\beta$-cell in the islet and organ community. Curr Opin Genet Dev. 2009;19(5):469-75.

13. Nikolova G, Jabs N, Konstantinova I, et al. The vascular basement membrane: a niche for insulin gene expression and $\beta$ cell proliferation. Dev Cell. 2006;10(3):397-405.

14. Nikolova G, Strilic B, Lammert E. The vascular niche and its basement membrane. Trends Cell Biol. 2007;17(1):19-25.

15. Otonkoski T, Banerjee M, Korsgren $\mathrm{O}$, et al. Unique basement membrane structure of human pancreatic islets: implications for $\beta$-cell growth and differentiation. Diabetes Obes Metabol. 2008;10:119-27.

16. Virtanen I, Banerjee M, Palgi J, et al. Blood vessels of human islets of langerhans are surrounded by a double basement membrane. Diabetologia. 2008;51(7):1181-91.

17. Wojtusciszyn A, Armanet M, Morel P, et al. Insulin secretion from human beta cells is heterogeneous and dependent on cell-to-cell contacts. Diabetologia. 2008;51(10):1843-52.

18. Gautam D, Han S-J, Hamdan FF, et al. A critical role for $\beta$ cell M3 muscarinic acetylcholine receptors in regulating insulin release and blood glucose homeostasis in vivo. Cell Metabol. 2006;3(6):449-61.

19. Unger RH, Orci L. Paracrinology of islets and the paracrinopathy of diabetes. Proc Natl Acad Sci U S A. 2010;107(37):16009-12.

20. Huypens P, Ling Z, Pipeleers D, et al. Glucagon receptors on human islet cells contribute to glucose competence of insulin release. Diabetologia. 2000;43(8):1012-101.

21. Bosco D, Armanet P, Morel P, et al. Unique arrangement of alpha cells and beta cells in human islets of Langerhans. Diabetes. 2010;59(5):1202-10.

22. Ahrén B. Autonomic regulation of islet hormone secretion-implications for health and disease. Diabetologia. 2000;43(4):393-410.

23. Drucker DJ. The role of gut hormones in glucose homeostasis. J Clin Investig. 2007;117(1):24-32.

24. Wang RN, Rosenberg L. Maintenance of beta-cell function and survival following islet isolation requires re-establishment of the islet-matrix relationship. J Endocrinol. 1999;163:181-90.

25. Vajkoczy P, Olofsson AM, Lehr HA, et al. Histogenesis and ultrastructure of pancreatic islet graft microvasculature. Evidence for graft revascularization by endothelial cells of host origin. Am J Pathol. 1995;146(6):1397-405.

26. Menger MD, Vajkoczy P, Leiderer R, et al. Influence of experimental hyperglycemia on microvascular blood perfusion of pancreatic islet isografts. J Clin Investig. 1992;90(4):1361-9.

27. Hirshberg B. Histopathological study of intrahepatic islets transplanted in the nonhuman primate model using edmonton protocol immunosuppression. J Clin Endocrinol Metab. 2002;87(12):54249.

28. Vasir B, Aiello LP, Yoon KH, et al. Hypoxia induces vascular endothelial growth factor gene and protein expression in cultured rat islet cells. Diabetes. 1998;47(12):1894-903.

29. Lai Y, Schneider D, Kidszun A, et al. Vascular endothelial growth factor increases functional beta-cell mass by improvement of angiogenesis of isolated human and murine pancreatic islets. Transplantation. 2005;79(11):1530-6.

30. Brissova M, Shostak A, Shiota M, et al. Pancreatic islet production of vascular endothelial growth factor-a is essential for islet vascularization, revascularization, and function. Diabetes. 2006;55(11):2974-85.
31. Bosco D, Meda P, Halban PA, et al. Importance of cell-matrix interactions in rat islet beta-cell secretion in vitro: role of alpha6beta1 integrin. Diabetes. 2000;49(2):233-43.

32. Hammar E, Parnaud G, Bosco D, et al. Extracellular matrix protects pancreatic $\beta$-cells against apoptosis. Diabetes. 2004;53 (8):2034-41.

33. Parnaud G, Hammar E, Ribaux $P$, et al. Signaling pathways implicated in the stimulation of beta-cell proliferation by extracellular matrix. Mol Endocrinol. 2009;23(8):1264-71.

34. Contreras J. Peripheral mobilization of recipient bone marrowderived endothelial progenitor cells enhances pancreatic islet revascularization and engraftment after intraportal transplantation. Surgery. 2003;134(2):390-8.

35. Nyqvist D, Köhler M, Wahlstedt $H$, et al. Donor islet endothelial cells participate in formation of functional vessels within pancreatic islet grafts. Diabetes. 2005;54(8):2287-93.

36. Miller R, Cirulli V, Diaferia GR, et al. Switching-on survival and repair response programs in islet transplants by bone marrow-derived vasculogenic cells. Diabetes. 2008;57(9): 2402-12.

37. Johansson U, Elgue G, Nilsson B, et al. Composite isletendothelial cell grafts: a novel approach to counteract innate immunity in islet transplantation. Am J Transplant. 2005;5 (11):2632-9.

38. Ianus A. In vivo derivation of glucose-competent pancreatic endocrine cells from bone marrow without evidence of cell fusion. J Clin Investig. 2003;111(6):843-50.

39. Hess D, Li L, Martin M, et al. Bone marrow-derived stem cells initiate pancreatic regeneration. Nat Biotechnol. 2003;21(7):763-70.

40. Sordi V, Piemonti L. The contribution of hematopoietic stem cells to beta-cell replacement. Curr Diabetes Rep. 2009;9 (2):119-24.

41. Sordi V, Malosio ML, Marchesi F, et al. Bone marrow mesenchymal stem cells express a restricted set of functionally active chemokine receptors capable of promoting migration to pancreatic islets. Blood. 2005;106(2):419-27.

42. Lee RH, Seo MJ, Reger RL, et al. Multipotent stromal cells from human marrow home to and promote repair of pancreatic islets and renal glomeruli in diabetic NOD/scid mice. Proc Natl Acad Sci U S A. 2006;103(46):17438-43.

43. Ezquer F, Ezquer M, Parrau D, et al. Systemic administration of multipotent mesenchymal stromal cells reverts hyperglycemia and prevents nephropathy in type 1 diabetic mice. Biol Blood Marrow Transplant. 2008;14(6):631-40.

44. Figliuzzi M, Cornolti R, Perico N, et al. Bone marrow-derived mesenchymal stem cells improve islet graft function in diabetic rats. Transplant Proc. 2009;41(5):1797-800.

45. Park KS, Kim YS, Kim JH, et al. Influence of human allogenic bone marrow and cord blood-derived mesenchymal stem cell secreting trophic factors on ATP (adenosine-5'-triphosphate)/ADP (adenosine-5'-diphosphate) ratio and insulin secretory function of isolated human islets from cadaveric donor. Transplant Proc. 2009;41(9):3813-8.

46. Lu Y, Jin X, Chen Y, et al. Mesenchymal stem cells protect islets from hypoxia/reoxygenation-induced injury. Cell Biochem Funct. 2010;28(8):637-43.

47. Jacobson S, Kumagai-Braesch M, Tibell A, et al. Co-transplantation of stromal cells interferes with the rejection of allogeneic islet grafts. Ann N Y Acad Sci. 2008;1150(1):213-6.

48. Ding Y, Xu D, Feng G, et al. Mesenchymal stem cells prevent the rejection of fully allogenic islet grafts by the immunosuppressive activity of matrix metalloproteinase-2 and -9. Diabetes. 2009;58 (8):1797-806.

49. Madec AM, Mallone R, Afonso G, et al. Mesenchymal stem cells protect NOD mice from diabetes by inducing regulatory $\mathrm{T}$ cells. Diabetologia. 2009;52(7):1391-9. 
50. Berman DM, Willman MA, Han D, et al. Mesenchymal stem cells enhance allogeneic islet engraftment in nonhuman primates. Diabetes. 2010;59(10):2558-68.

51. Capila I, Linhardt RJ. Heparin-protein interactions. Angew Chem Int Ed. 2002:41:390-412.

52. Cabric S, Sanchez J, Lundgren T, et al. Islet surface heparinization prevents the instant blood-mediated inflammatory reaction in islet transplantation. Diabetes. 2007;56(8):2008-15.

53. • Cabric S, Sanchez J, Johansson U, et al. Anchoring of vascular endothelial growth factor to surface-immobilized heparin on pancreatic islets: implications for stimulating islet angiogenesis. Tissue Eng Part A. 2010;16(3):961-70. This paper showed the immobiliziation of heparin and VEGF-A to islets allowing adhesion of endothelial cells and unaffected insulin release.

54. Rajangam K, Behanna HA, Hui MJ, et al. Heparin binding nanostructures to promote growth of blood vessels. Nano Lett. 2006;6(9):2086-90.

55. Stendahl JC, Wang L-J, Chow LW, et al. Growth factor delivery from self-assembling nanofibers to facilitate islet transplantation. Transplantation. 2008;86(3):478-81.

56. Chow LW, Wang L-J, Kaufman DB, et al. Self-assembling nanostructures to deliver angiogenic factors to pancreatic islets. Biomaterials. 2010;31(24):6154-61.

57. Freudenberg U, Hermann A, Welzel PB, et al. A star-PEG-heparin hydrogel platform to aid cell replacement therapies for neurodegenerative diseases. Biomaterials. 2009;30(28):5049-60.

58. Sodergard A, Stolt M. Properties of lactic acid based polymers and their correlation with composition. Prog Polym Sci. 2002;27:1123-63.

59. Dufour JM, Rajotte RV, Zimmerman M, et al. Development of an ectopic site for islet transplantation, using biodegradable scaffolds. Tissue Eng. 2005;11(9/10):1323-31.

60. Blomeier H, Zhang X, Rives C, et al. Polymer scaffolds as synthetic microenvironments for extrahepatic islet transplantation. Transplantation. 2006;82(4):452-9.

61. - Kin T, O'Neil JJ, Pawlick R, et al. The use of an approved biodegradable polymer scaffold as a solid support system for improvement of islet engraftment. Artif Organs. 2008;32(12):990 93. Using a Food and Drug-approved synthetic absorable implant laden with autogenic islets, the authors show the improvement in glycemia of pancreatectomized dogs.

62. Yang X-D, Li H-M, Chen M, et al. Enhanced insulin production from murine islet beta cells incubated on poly(3-hydroxybutyrate-co-3hydroxyhexanoate). J Biomed Mater Res. 2009;92A(2):548-55.

63. Kloxin AM, Kloxin CJ, Bowman CN, et al. Mechanical properties of cellularly responsive hydrogels and their experimental determination. Adv Mater. 2010;22(31):3484-94.

64. Ito M, Taguchi T. Enhanced insulin secretion of physically crosslinked pancreatic $\beta$-cells by using a poly(ethylene glycol) derivative with oleyl groups. Acta Biomater. 2009;5(8):2945-52.

65. Totani T, Teramura Y, Iwata H. Immobilization of urokinase on the islet surface by amphiphilic poly(vinyl alcohol) that carries alkyl side chains. Biomaterials. 2008;29(19):2878-83.

66. Shimizu H, Ohashi K, Utoh R, et al. Bioengineering of a functional sheet of islet cells for the treatment of diabetes mellitus. Biomaterials. 2009;30(30):5943-9.

67. Williams SJ, Wang Q, MacGregor RR, et al. Adhesion of pancreatic beta cells to biopolymer films. Biopolymers. 2009;91 (8):676-85.

68. - Mei Y, Hollister-Lock J, Bogatyrev SR, et al. A high throughput micro-array system of polymer surfaces for the manipulation of primary pancreatic islet cells. Biomaterials. 2010;31(34):8989-95. An elegant high-throughput system is reported to study polymer surfaces for islet cell attachment.

69. Scharp DW, Mason NS, Sparks RE. Islet immuno-isolation: the use of hybrid artificial organs to prevent islet tissue rejection. World J Surg. 1984;8:221-9.
70. Scharp DW, Swanson CJ, Olack BJ, et al. Protection of encapsulated human islets implanted without immunosuppression in patients with type I or type II diabetes and in nondiabetic control subjects. Diabetes. 1994;43(9):1167-70.

71. Clark H, Barbari TA, Stump K, et al. Histologic evaluation of the inflammatory response around implanted hollow fiber membranes. J Biomed Mater Res. 2000;52:183-92.

72. Dulong JL, Legallais C, Darquy S, et al. A novel model of solute transport in a hollow-fiber bioartifical pancreas based on a finite element method. Biotechnol Bioeng. 2002;78(5):576-82.

73. Kawakami Y, Iwata H, Gu Y, et al. Modified subcutaneous tissue with neovascularization is useful as the site for pancreatic islet transplantation. Cell Transplant. 2000;9(5):729-32.

74. de Vos P, de Haan BJ, Wolters GH, et al. Improved biocompatibility but limited graft survival after purification of alginate for microencapsulation of pancreatic islets. Diabetologia. 1997;40 (3):262-70.

75. Sakurai T, Satake A, Nagata N, et al. The development of new immunoisolatory devices possessing the ability to induce neovascularization. Cell Transplant. 2003;12(5):527-35. 9.

76. Pileggi A, Molano RD, Ricordi C, et al. Reversal of diabetes by pancreatic islet transplantation into a subcutaneous, neovascularized device. Transplantation. 2006;81(9):1318-24.

77. •• Ludwig B, Zimerman B, Steffen A, et al. A novel device for islet transplantation providing immune protection and oxygen supply. Horm Metab Res. 2010;42(13):918-22. The authors report an extravascular device in which optimized oxygen levels are delivered to immunoprotected islets in a minipig model.

78. Chick W, Like A, Lauris V. Beta cell culture on synthetic capillaries: an artificial endocrine pancreas. Science. 1975;187 (4179):847-9.

79. Sun AM, Parisius W, Healy GM, et al. The use, in diabetic rats and monkeys, of artificial capillary units containing cultured islets of langerhans (artificial endocrine pancreas). Diabetes. 1977;26 (12):1136-9.

80. Sullivan SJ, Maki T, Borland KM, Mahoney MD, et al. Biohybrid artificial pancreas: long-term implantation studies in diabetic, pancreatectomized dogs. Science. 1991;252:718-21.

81. Maki T, Lodge JP, Carretta M, et al. Treatment of severe diabetes mellitus for more than one year using a vascularized hybrid artificial pancreas. Transplantation. 1993;55(4):713-7.

82. Maki T, Otsu I, O'Neil JJ, et al. Treatment of diabetes by xenogeneic islets without immunosuppression. Use of a vascularized bioartificial pancreas. Diabetes. 1996;42(33):342-7.

83. Cronin KJ, Messina A, Knight KR, et al. New murine model of spontaneous autologous tissue engineering, combining an arteriovenous pedicle with matrix materials. Plast Reconstr Surg. 2004;113(1):260-9.

84. Hussey AJ, Winardi M, Han XL, et al. Seeding of pancreatic islets into prevascularized tissue engineering chambers. Tissue Eng Part A. $2009 ; 15(12): 3823-33$.

85. Hussey AJ, Winardi M, Wilson $\mathrm{J}$, et al. Pancreatic islet transplantation using vascularised chambers containing nerve growth factor ameliorates hyperglycaemia in diabetic mice. Cells Tissues Organs. 2010;191(5):382-93.

86. Calafiore R, Luca G, Calvitti M, et al. Cellular support systems for alginate microcapsules containing islets, as composite bioartificial pancreas. Ann N Y Acad Sci. 2001;944:240-51.

87. Lim F, Sun AM. Microencapsulated islets as bioartificial endocrine pancreas. Science. 1980;210(4472):908-10.

88. Lum ZP, Tai IT, Krestow M, et al. Prolonged reversal of diabetic state in NOD mice by xenografts of microencapsulated rat islets. Diabetes. 1991;40(11):1511-6.

89. Fan MY, Lum ZP, Fu XW, et al. Reversal of diabetes in BB rats by transplantation of encapsulated pancreatic islets. Diabetes. 1990;39(4):519-22. 
90. Calafiore R, Basta G, Luca G, et al. Alginate/polyaminoacidic coherent microcapsules for pancreatic islet graft immunoisolation in diabetic recipients. Ann N YAcad Sci. 1997;831:313-22.

91. Soon-Shiong P, Feldman E, Nelson R, et al. Long-term reversal of diabetes by injection of immunoprotected islets. Proc Natl Acad Sci U S A. 1993;90:5843-7.

92. Soon-Shiong P, Heintz RE, Merideth N, et al. Insulin independence in a type 1 diabetic patient after encapsulated islet transplantation. Lancet. 1994;343(8903):950-1.

93. Figliuzzi M, Plati T, Cornolti R, et al. Biocompatibility and function of microencapsulated pancreatic islets. Acta Biomater. 2006;2(2):221-7.

94. Safley SA, Kapp JA, Weber CJ. Proliferative and cytokine responses in CTLA4-Ig-treated diabetic NOD mice transplanted with microencapsulated neonatal porcine ICCs. Cell Transplant. 2002;11(7):695-705.
95. Safley SA, Kapp LM, Tucker-Burden C, et al. Inhibition of cellular immune responses to encapsulated porcine islet xenografts by simultaneous blockade of two different costimulatory pathways. Transplantation. 2005;79(4):409-18.

96. Cui H, Tucker-Burden C, Cauffiel SMD, et al. Long-term metabolic control of autoimmune diabetes in spontaneously diabetic nonobese diabetic mice by nonvascularized microencapsulated adult porcine islets. Transplantation. 2009;88(2):160-9.

97. Calafiore R, Basta G, Luca G, et al. Grafts of microencapsulated pancreatic islet cells for the therapy of diabetes mellitus in nonimmunosuppressed animals. Biotechnol Appl Biochem. 2004;39 (23):159-64.

98. Lutolf MP, Hubbell JA. Synthetic biomaterials as instructive extracellular microenvironments for morphogenesis in tissue engineering. Nat Biotechnol. 2005;23(1):47-55. 